\title{
Diversity of vertebrate and invertebrate scavenging commu- nities of reptile carcasses in the piedmont of North Carolina, USA
}

\author{
Shem Unger*, Zeb Hull \& Mark Rollins \\ ${ }^{1}$ Department of Biology, Wingate University, Wingate, North Carolina, USA \\ *Corresponding author, e-mail: s.unger@wingate.edu
}

Scavenging of animal carcasses (carrion) is an important ecological process, which occurs when insects and vertebrates either aid in decomposition or removal of carcasses. However, very little is known regarding which species typically scavenge or which forensically important insects colonize recently deceased reptile carrion and in what relative frequencies. To this end, we deployed three reptile carcasses, a box turtle (Terrapene carolina), a snapping turtle (Chelydra serpentina), and black rat snake (Pantherophis obsoletus) near a road and monitored vertebrate and invertebrate scavengers visiting carcasses with non-invasive camera traps and manual collection of insects visiting carcasses during the Spring of 2018 near Wingate, North Carolina, USA. In total, we collected 233 invertebrates present on the carcass by hand net capture representing 14 taxonomic insect groupings and observed 16 vertebrate species (mammals and birds) from 86 observations scavenging on the remains, with white-footed deer mouse (Peromyscus leucopus), and Virginia opossum (Didelphis virginiana) being the most frequent vertebrate scavengers detected on camera traps. Carcasses were colonized by several insects including the orders Coleoptera from families Silphidae carrion beetles (Oiceoptoma noveboracense and Oiceoptoma inequale) and Staphylinidae (Platydracus sp.), the order Diptera representing families Piophilidae (Prochyliza sp.), Calliphoridae (Calliphora sp. and Luicilla sp.), Muscidea (Musca sp.), and Stratiomyidae (Hermetia sp.) and order Hymenoptera family Formicidae (Prenolepsis sp.). This report adds to our knowledge on the biodiversity of both invertebrate and vertebrate scavenging guild communities which rely on reptile carrion as an ecological resource in terrestrial semi-forested environments.

KEY WORDS

Carrion ecology; forensic entomology; scavenger diversity; insect community; camera traps.

Received 06.02.2019; accepted 16.03.2019; published online 28.03.2019

\section{INTRODUCTION}

The decomposition of vertebrate carcasses (carrion) can generate a great deal of biological activity and have important ecological impacts, with carcass nutrients supporting populations of both microbial, insect, and vertebrates (scavengers) in nature (Van-
Laerhoven \& Anderson, 1999; Melis et al., 2004; Carter et al., 2007; Beasley et al., 2012). Moreover, reptiles are often the victims of direct mortality in both urban and semi-rural environments and near protected areas as a result of roads, with common roadkill mortality including snapping turtles, Chelydra serpentina (Linnaeus, 1758), box turtles Ter- 
rapene carolina (Linnaeus, 1758), and Pantherophis obsoletus (James, 1823), the black rat snake (Haxton, 2000; Smith \& Dodd, 2003; Row et al., 2007; Andrews et al., 2008). The availability of carrion can influence local diversity and food webs of vertebrate scavengers as well as insects in urban ecosystems (Inger et al., 2016; Schwartz et al., 2018). However, very little research has assessed the biodiversity of both carcass insect colonizers and vertebrate scavengers which in the short term may rely on road mortality reptiles as either a nutrient resource or as a location for deposition of eggs by a variety of insects.

There are diverse groups of forensically important, necrophagous insects which colonize carrion (Amendt et al., 2007), including primarily members of the insect orders Diptera and Coleoptera (Benecke, 2001; Kulshreshta \& Satpathy, 2001). Camera traps (trail cameras) are useful to non-invasively monitor wildlife populations and scavenging behavior in mammals (Devault et al., 2004; Pomezanski \& Bennett, 2018; Schlichting et al., 2019). Presently, there is a dearth of information on either the frequency of reptile carrion scavenged by local wildlife (Antworth et al., 2005; Abernathy et al., 2017) or the extent of insect colonization on reptile carcasses (Watson \& Carlton, 2005a, b). Moreover, in addition to mammals, both traditional scavenging and opportunistic species of birds may frequent carcasses (Inger et al., 2016), indicating carrion may help maintain local biodiversity across multiple taxonomic groups. In addition, most studies on forensic entomology rely on using the mammalian porcine model (Sus scrofa Linnaeus, 1758) as a carcass, with little knowledge available on other types of vertebrate carcass types which may also be utilized by local organismal communities (Schoenly et al., 2006). The aim of this work is to identify the diversity of scavenging vertebrates and colonizing invertebrates (forensic entomology) of reptile carcasses using both non-invasive camera traps and direct sampling of insects colonizing carcass.

\section{MATERIAL AND METHODS}

\section{Field Sampling}

During the Spring of 2018, we deployed three reptile carcasses, one black rat snake (Pantherophis obsoletus), and two turtle species, an eastern box turtle (Terrapene carolina) and common snapping turtle (Chelydra serpentina) on 10.IV.2018, 10.IV.2018 and 27.III.2018, respectively in the central Piedmont area of Wingate, North Carolina, USA. All carcasses were collected recently deceased (under $~ 12$ hours at the same location). Animals were obtained in coordination of North Carolina Wildlife Resources Commission, doublebagged and frozen until deployed. Carcasses were deployed in a wooded area at Wingate University Campus Lake area (latitude 34,988 and longitude 80,429; 170 meters elevation), a mixture of Quercus and Pinus forest, within 20 meters of roads but in a wooded area to simulate roadkill conditions. Each carcass was separated by a minimal distance of 50 meters to prevent cross contamination by insects following Perez et al. (2016). For each carcass, we deployed a total of three trail cameras positioned at varying angles of carcass to maximize detection of potential scavengers and in close enough proximity to differentiate smaller organisms. A small area of the leaf litter was cleared and carcasses were placed in the center of a trail camera array consisting of three Bushnell trail cameras (model 119637C) positioned facing the carcass area secured to nearby trees. This array allowed multiple angles of trail cameras in case images were blurry for any one trail camera. Cameras were set to record in $24 \mathrm{hr}$ mode, motion capture at medium LED control, $14 \mathrm{M}$ pixel, and 3 images per event. Cameras were deployed until 9.V.2018, to allow documentation of mammalian and bird visitors to carcasses at later decomposition stages (post-decay/dry stage; Kreitlow, 2010) and to detect potentially rare mammalian species (i.e., skunk, etc.), with low probabilities of detection (Shannon et al., 2014). We also recorded daily temperatures using $\mathrm{HOBO}{ }^{\circledR}$ temperature data loggers during the experiment.

We visited carcasses daily during the first week of deployment, then periodically (every two days) following the first week for 26 days to collect insects actively scavenging or on the surface, or immediately below ground of each carcass. Insects scavenging carcass were collected using a combination of forceps, a sweep net, and insect aspirator and stored in $95 \%$ ethanol until identification. We were careful when collecting insects to never re- 
move more than five individuals of any one species per carcass to prevent compromising colonization of carcass by other insects and decomposition rates.

\section{Data Analysis}

We identified insects on carcasses to the lowest taxonomic level possible. We calculated the species richness and Shannon Diversity index for insects collected. We reviewed trail camera images to identify the frequency of carcass visitations by mammals and birds. Each of the three trail cameras were viewed by authors and the best image for identification was used to validate species level identification and time of visit to each carcass type. We characterized images (visits by birds or mammals) captured by camera traps as temporally independent (a single observation) if they were separated by a minimum of $30 \mathrm{~min}$ utes. However, we have no information if the same individual repeatedly visited a single carcass, and therefore report this information as observations.

\section{RESULTS}

In total, we detected 16 mammal species (86 individual observations) visiting our carcasses (Fig. 1), with one, the Virginia opossum, Didelphis virginiana (Kerr, 1792), fully removing and consuming our black rat snake carcass on the seventh day, on 16.IV.2018 (Fig. 1). Both turtle carcasses remained present through various decomposition stages. We also observed Raccoon, Procyon lotor (Linnaeus, 1758) (Fig. 2), Grey Fox, Urocyon cinereoargenteus (Schreber, 1775) (Fig. 3), Turkey Vulture, Cathartes aura (Linnaeus, 1758) (Fig. 4), and Striped Skunk, Mephitis mephitis (Schreber, 1776), visiting carcasses. Across carcass types, the white-footed deer mouse, Peromyscus maniculatus (Wagner, 1845), accounted for the most visits to carcasses, with Virginia opossum, D. virginiana, Eastern grey squirrel, Sciurus carolinensis Gmelin, 1788, and Northern Cardinal, Cardinalis cardinalis (Linnaeus, 1758) among the most frequent mammalian and bird observations on camera traps (Fig. 5). Additional species (Fig. 6) which visited

\begin{tabular}{|lclll|}
\hline Carcass Type & Frequency & Order & Family & Taxon \\
\hline CS, TC, & 40 & Coleoptera & Silphidae & Oiceoptoma noveboracense (Forster, 1771) \\
CS, TC, PO & 13 & & & Oiceoptoma inequale (Fabricius, 1781) \\
PO & 1 & & & Thanatophilus lapponicus (Herbst, 1793) \\
TC & 1 & & Scarabaeidae & Onthophagus sp. \\
CS, TC & 4 & & Staphylinidae & Platydracus sp. \\
CS & 39 & Diptera & Piophilidae & Prochyliza sp. \\
PO, CS & 8 & & Calliphoridae & Lucilla sericata \\
CS & 2 & & & Calliphora sp. \\
CS, TC & 17 & & Muscidea & Musca domesticus (Linnaeus, 1758) \\
CS & 7 & & Stratiomyidae & Hermetia sp. \\
CS & 1 & & Sarcophagidae & Sarcophaga sp. \\
CS, TC & 41 & & unknown & instars \\
PO, TC & 21 & Hymenoptera & Formicidae & Prenolepsis sp. \\
CS & 2 & & & Formica sp. \\
CS & 1 & Blattodea & Blattidea & Parcoblatta sp. \\
\hline Total & 198 & & & \\
Species richness & 14 & & & \\
Shannon Diversity index & 1.797 & & & \\
\hline
\end{tabular}

Table 1. Insects identified on carcass by type (Chelydra serpentina [CS], Terrapene carolina [TC], and Pantherophis obsoletus [PO]), frequency, and taxonomic designation. Note: unknown Diptera or non-insect arthropods not included in species richness or Shannon Diversity Index calculations. 


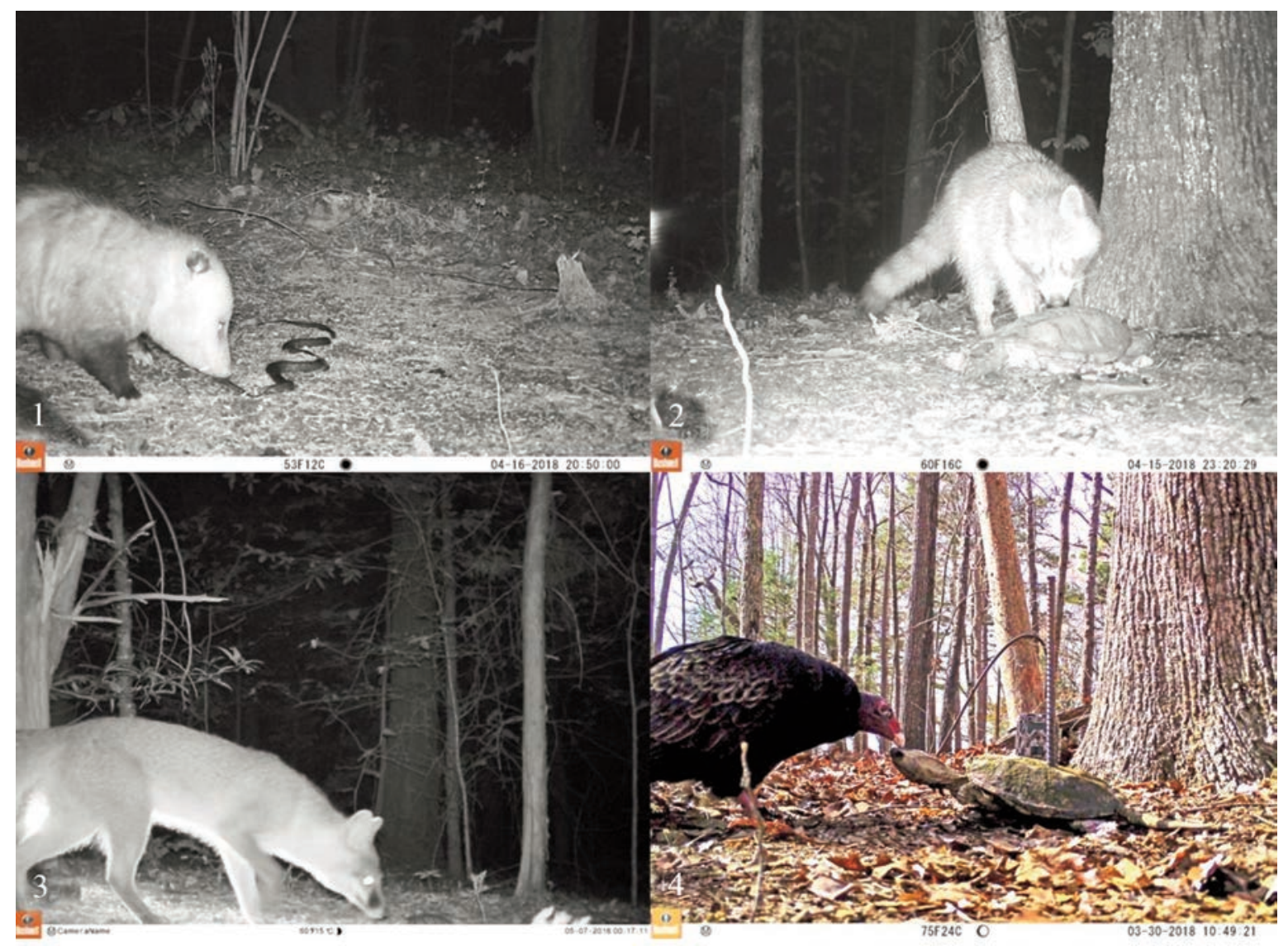

Figures 1-4. Examples of Trail Camera images showing scavengers, including common opossum on rat snake (Fig. 1), raccoon on snapping turtle (Fig. 2), grey fox on box turtle (Fig. 3), and turkey vulture on snapping turtle (Fig. 4).

the carcasses included the Brown thrasher, Toxostoma rufum (Linnaeus, 1758), Eastern cottontail rabbit, Sylvilagus floridanus (J.A. Allen, 1890), White-tailed deer, Odocoileus virginianus (Zimmermann, 1780), Domestic cat, Felis catus (Linnaeus, 1758), Brown-headed cowbird, Molothrus ater (Boddaert, 1783), American robin, Turdus migratorius Linnaeus, 1766, American crow, Corvus brachyrhynchos Brehm, 1822, and Carolina wren, Thryothorus ludovicianus (Latham, 1790). In total, camera traps recorded 5,459 images (three camera traps per carcass) with 2,212 images for box turtle carcass, 1,427 images for rat snake carcass, and 1,820 images for the snapping turtle carcass. Many images represented pictures with no bird or mammal individuals present or duplicate images of the same organism visiting carcasses from multiple camera traps. In addition, several images depicted larger fly adults and carrion beetle adults visiting carcasses, but image quality was of low resolution based on the distance of trail camera to carcass for identification further than Diptera or Coleoptera and are not included in this study. These 86 mammalian and bird observations consisted of $52 \mathrm{ob}-$ servations on the box turtle, 21 observations on the snapping turtle carcass, and only 13 observations on the snake carcass. The majority of camera trap images were recorded each day during 20:00 to 5:00 hours, or nocturnal and crepuscular (Fig. 7). Temperatures during the experiment (insect collection and camera trapping) ranged from average minimal lows of $8.6^{\circ} \mathrm{C}$ to average maximum daily temperatures of $22.1^{\circ} \mathrm{C}$.

We identified 17 taxonomic groups of invertebrates (14 insect groupings) associated with our three reptile carcasses, albeit at different frequencies (Table 1). We observed three insect orders across carcasses: Coleoptera, Diptera and Hymenoptera. Insect families present on the snake carcass included Silphidae, Calliphoridae, and 


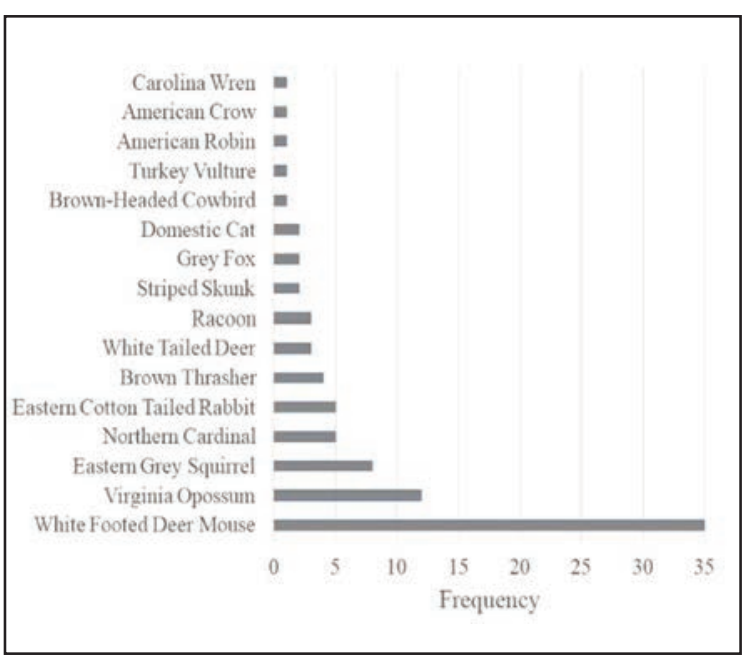

Figure 5. Relative frequency of vertebrate scavengers observed on camera traps.

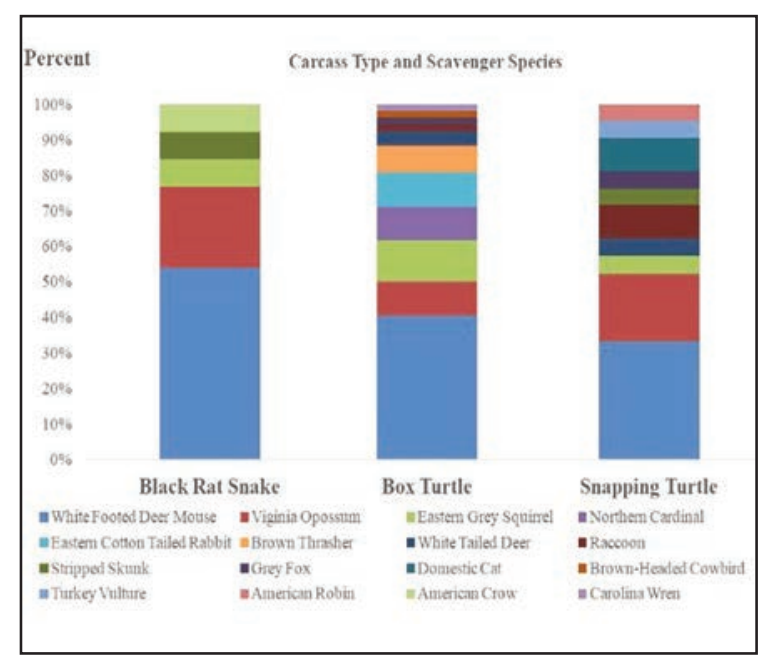

Figure 6. Percentage of scavenger species (vertebrates: birds and mammals) observed on individual carcass type.

Formicidae, with five insect families present on the box turtle: Silphidae, Formicidae, Muscidae, Staphylinidae, and Scarbaeidae. The snapping turtle carcass comprised the most amount of insect families represented by Silphidae, Staphylinidae, Piophilidae, Formicidae, Calliphoridae, Muscidea, Sarcophagidae, Stratiomyidea, and Blattidea (Table 1; Fig. 8). We observed adult and larval Coleopterans Oiceoptoma inaequale and Oiceoptoma noveboracense on both species of turtles (Figs. 9, 10), several Dipteran fly adults, including Lucilia sericata on the rat snake (Fig. 11), and Musca domes-

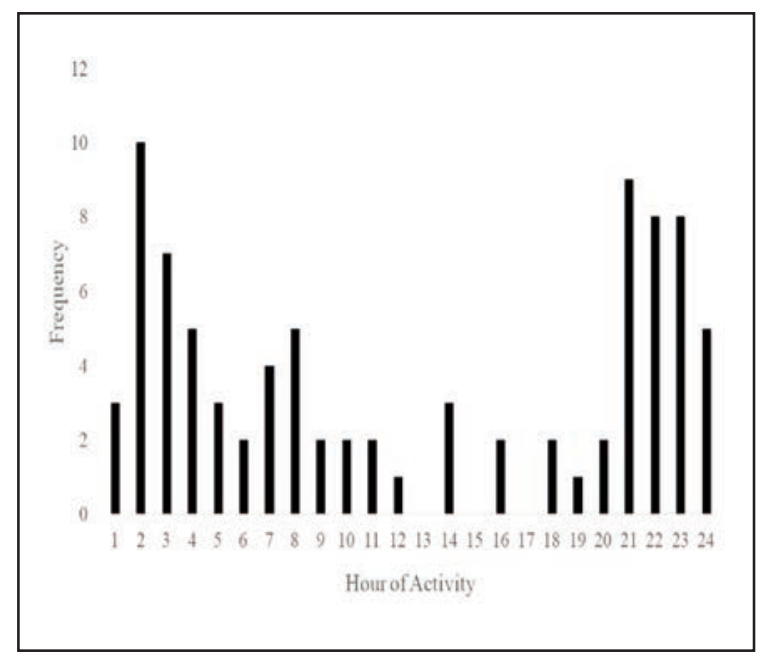

Figure 7. Frequency of camera trap observations of mammals and birds plotted against hour of activity.

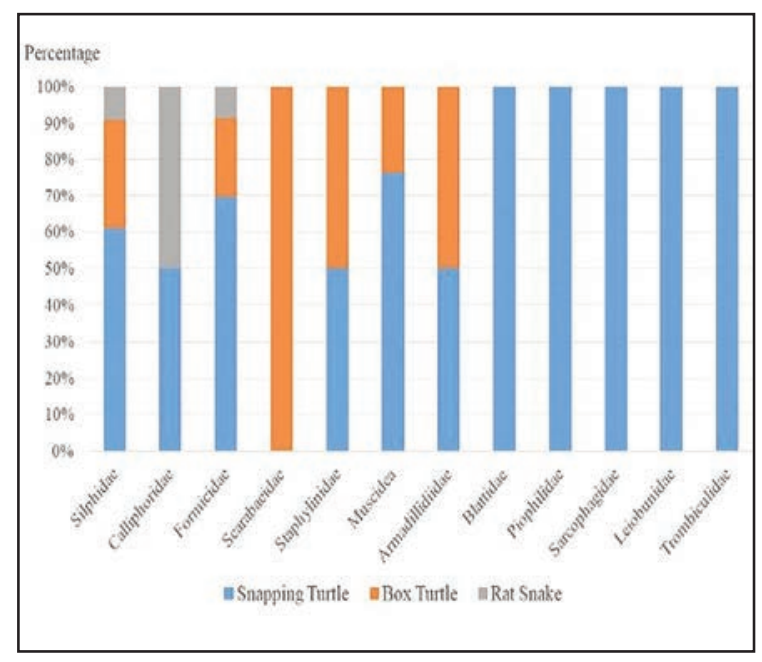

Figure 8. Relative frequencies of Insect families identified across carcass types.

tica on snapping turtle (Fig. 12) when visiting carcasses and also identified in the insects we collected. Many of the Oiceoptoma inaequale adults we observed when visiting the rat snake carcass were breeding directly on and even in the carcass (Fig. 9). We first observed fly instars (maggots) on the box turtle and snapping turtle at day 7 and day 9 , respectively, with none observed on the rat snake. In addition to insects, we further identified other arthropods present on carcasses, including 14 and 16 Armadillium vulgare (Order Isoptera, Family Armadillidiidae) on box turtle carcass and snap- 
ping turtle carcass, respectively. Lastly we collected 3 harvestmen Leiobunum sp. (Order Opiliones, Family Leiobunidae) and 2 harvest mites Trombicula sp. (Order Trombidiformes, Family Trombiculidae) on the snapping turtle carcass. We observed an increase in arthropods collected on decomposition days 7-9 and 14-17 (Fig. 13). Shannon Diversity Index for identified insects across all carcasses was 1.797 .

\section{DISCUSSION AND CONCLUSIONS}

This study detected a diverse set of organisms, both invertebrate and vertebrates, which differentially utilize reptile carcasses in a semi-forested ecosystem. Our most frequently sighted organism on camera traps, the white-footed deer mouse, is among smaller mammals encountered investigat- ing and scavenging on carcasses (O'Brien et al., 2007). We also noted similar to other studies in urban wooded areas, raccoons and Virginia opossums visiting carcasses (DeVault et al., 2004; Hager et al., 2012). In addition, we observed our black rat snake carcass to be scavenged within a short period (6 days), as other studies have found snakes to be scavenged within 36 hours (Antworth et al., 2005). We detected several species of passerine birds and rodents, which other studies have documented to scavenge remains (Pokines \& Pollock, 2018). Other studies on pig, Sus scrofa carcasses have observed high visitations by rodents as well as birds in the family Corvidae (Komar \& Beattie, 1998). It is possible we detected several bird species other than the turkey vulture on camera traps that were attracted to the smell of the carcass or that were feeding on insects that were present on or near the carcass. Moreover,

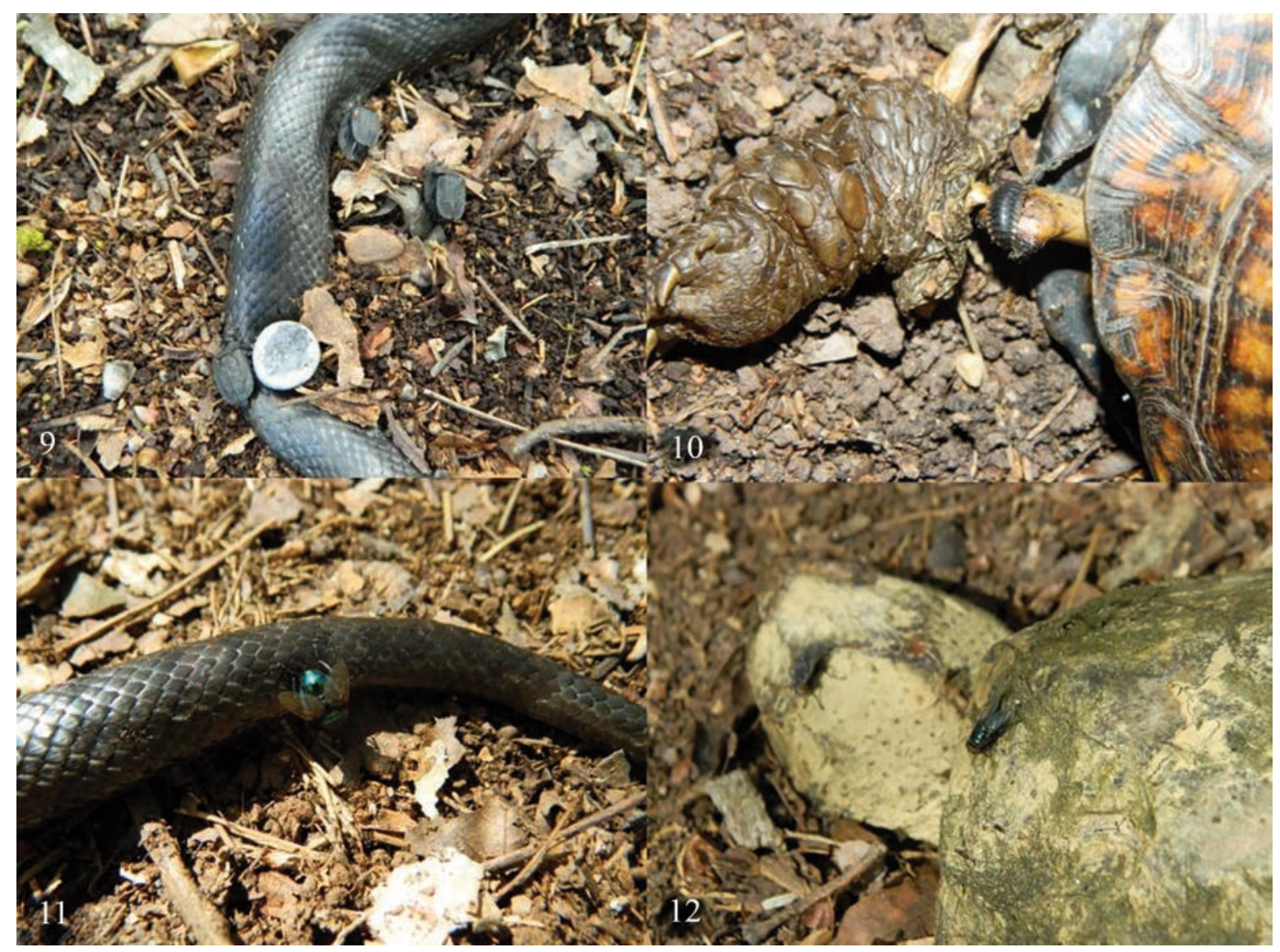

Figures 9-12. Example of invertebrates colonizing carcasses, including Oiceoptoma inaequale on rat snake (Fig. 9), Oiceoptoma noveboracense larvae on box turtle (Fig. 10), Lucilia sericata on rat snake (Fig. 11), and Musca domestica on snapping turtle (Fig. 12). 


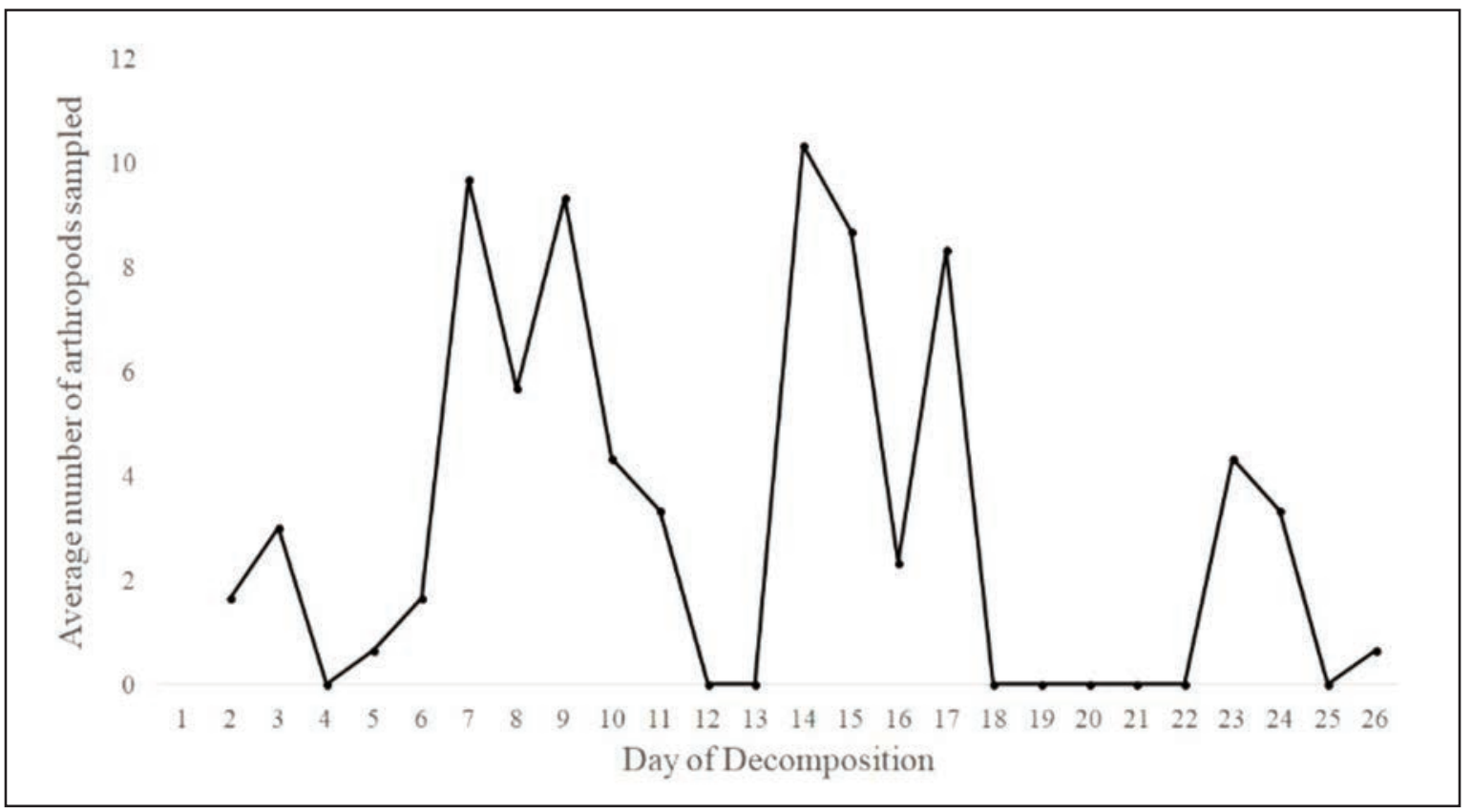

Figure 13. The average number of arthropods sampled across all carcass types during the experiment plotted against the day of decomposition. We noted an increase in arthropod activity within days 7-9 and 14-17.

we detected two separate taxonomic groupings of ants on carcasses, which can both directly consume carcasses material and affect colonization by other insects by lacerating carcasses (Eubanks et al., 2019).

We identified several groups of carrion-associated Coleoptera and Diptera across carcasses. The majority of carcasses were dominated by the presence of Oiceoptoma sp. adults and larvae and also insects from the Dipteran family Calliphoridae, both frequent colonizers of carrion (Michaud \& Moreau, 2017). We observed many members of the insect family Piophilidae, which are forensically important necrophagous species used to estimate the postmortem interval in forensics (Rochefort et al., 2015). Moreover, many of the Calliphoridae (blow flies) we detected, including Lucilia sericata, utilize carrion as breeding sites (Smith \& Wall, 1997), and are typically found in high relative abundances on pig carcasses used in forensic entomology (Gruner et al., 2007). One of the few studies on insect colonization of reptiles using the American alligator, Alligator mississippiensis, found both adult and instars of Calliphoridae within the first 6 to 7 days of decomposition (Watson \& Carlton, 2005b). We collected adult Cal- liphoridae within the first 3 days of decomposition for two of our carcasses, the snapping turtle and rat snake. Our results for many of the invertebrate scavengers are similar to other studies (Cammack et al., 2016; Cruise et al., 2018), for many of the same indicator insect groups on porcine remains, although we did not detect the American carrion beetle Necrophila americana, on any of our carcasses, as it may be a late carcass colonizer (Watson \& Carlton, 2005a). Interestingly, we also detected the Coleopteran Platydracus sp., which is suspected of preying on dipterans (Byrd \& Castner, 2000 ) indicating the potential importance of carrion as a resource not only for insect egg deposition, but predation by other insects. Our observation of Dipteran instars on both turtle carcasses within 7 to 9 days after carcass deployment, indicate potentially several species of flies deposited offspring on carrion. We did not detect Dipteran or Oiceoptoma sp. larvae on the rat snake carcass, likely due to this carcass being scavenged completely and removed from our experiment by a scavenger ( $D$. virginiana) on the seventh day of deployment, or possibly not enough time for development. However, in our visits to the snake carcass, we confirmed the presence of Oiceoptoma sp. 
adults breeding near, on, and even inside the snake carcass (Fig. 9), which was also validated on at least one camera trap. This observation indicates the potential for future work utilizing camera traps to monitor not just bird and mammal vertebrates, but also smaller-sized insect colonizers of carrion, particularly as trail camera video and image quality improves and becomes more affordable to biologist documenting local biodiversity. For example, camera traps could be placed within $\sim 0.25 \mathrm{~m}$ and set to record video and still photos at specific time intervals of a carcass to non-invasively identify insect colonizers and monitor frequency of visitations by adult insects.

The diversity of invertebrates and vertebrate scavengers present in our study represent dominant scavengers of not only reptiles but likely also other types of carrion in the local ecosystem. Furthermore, our observations for camera trap encounters, which occurred primarily nocturnally for mammals and during early mornings for birds, indicate activity patterns of scavengers, some of which were less abundant and seen less frequently on specific carcasses. Therefore, our data indicate that camera traps are effective for monitoring scavengers in semi-forested ecosystems and that reptile carrion is an essential resource in local food webs. In addition, using camera traps allows for the detection of animals that are more likely to flee from carrion as researchers approach carcasses to collect insects. Future work could incorporate further documentation of the micro-ecosystem and ecological cascade that forms around carrion. For example, as the number of insects colonizing a carcass increases, bird activity concomitantly increases due to the availability of invertebrate prey, in addition to scavenging by a variety of mammals.

The goal of this study was to provide preliminary data on reptile carcasses utilization as a carrion resource, which have been understudied in both forensic entomology and scavenging ecology. Our results on the snake carcass are limited due to it being scavenged and removed. Subsequently, future research should focus on examining the role of additional types of reptiles (e.g., lizards), and also increasing sample size to better understand if either insects or mammals colonize and scavenge reptiles similar to other carrion. Moreover, experimental carcasses could be deployed in protective cages to prevent removal by mammalian scavengers, as we observed with the rat snake. We observed the greatest number of individual insects and family diversity on the snapping turtle carcass, possibly due to its overall larger size compared to the smaller box turtle and snake carcasses or due to this carcass being placed $\sim 2$ weeks prior to the box turtle and snake carcasses. However, our overall results across carrion types provide baseline information on many of the same insect orders which have been observed in other studies (Cammack et al., 2016), with waltzing flies, Prochyliza sp. (Diptera) and the carrion beetle Oiceoptoma sp. (Coleoptera) being dominant colonizers of reptile carrion. We conclude, based on our data observations, that reptile carrion may help maintain local biodiversity across trophic levels of both vertebrates and invertebrate communities, including a variety of insect, mammal, and bird species.

\section{ACKNOWLEDGEMENTS}

We thank the Wingate University Biology Department for providing resources for this project. The North Carolina Division of Wildlife Resources was consulted for collection of carcasses. Insects are deposited in the Wingate University Biology Department insect collection. We followed animal care and used guidelines of the Wingate University Research and Review Board.

\section{REFERENCES}

Abernathy E.F., Turner K.L., Beasley J.C. \& Rhodes O.E. Jr., 2017. Scavenging along an ecological interface: utilization of amphibian and reptile carcasses around isolated wetlands. Ecosphere, 8: 1-12.

Andrews K.M., Gibbons J.W. \& Jochimsen D.M., 2008. Ecological effects of roads on amphibians and reptiles: a literature review. In: Urban Ecology, Mitchell J.C., Brown R.R. J. \& Bartholomew B., Society for the Study of Amphibians and Reptiles, pp. 121-143.

Amendt J., Campobasso C.P., Guadry E., Reiter C., LeBlanc H.N. \& Hall M.J.R., 2007. Best practices in forensic entomology-standards and guidelines. International Journal of Legal Medicine, 121: 90-104. https://doi.org/10.1007/s00414-006-0086-x

Antworth R.L., Pike D.A. \& Stevens E.E., 2005. Hit and Run: Effects of scavenging on estimates of roadkilled vertebrates. Southeastern naturalist, 4: 647-656. 
Beasley J.C., Olson Z.H. \& Devault T.L., 2012. Carrion cycling in food webs: comparisons among terrestrial and marine ecosystems. Oikos, 121: 1021-1026. https://doi.org/10.1111/j.1600-0706.2012.20353.x

Benecke M., 2001. A brief history of forensic entomology. Forensic Science International, 120: 2-14.

Byrd J.H. \& Castner J.L., 2000. Forensic Entomology: the utility of arthropods in legal investigations. CRC Press, Boca Raton, Florida, 705 pp.

Cammack J.A., Cohen A.C., Kreitlow K.L. \& Watson D.W., 2016. Decomposition of concealed and exposed porcine remains in the North Carolina Piedmont. Journal of Medical Entomology, 53: 67-75. https://doi.org/10.1093/jme/tjv183

Carter D.O., Yellowlees D. \& Tibbett M., 2007. Cadaver decomposition in terrestrial ecosystems. Naturewissenschaftenm, 94: 12-24. https://doi.org/10.1007/ s00114-006-0159-1

Cruise A., Watson D.W. \& Schal C., 2018. Ecological succession of adult necrophilus insects on neonate Sus scrofa domesticus in central North Carolina. PLoS ONE 13, e0195785. https://doi.org/10.1371/ journal.pone.0195785

DeVault T.L., Brisbin I.L. \& Rhodes O.E., 2004. Factors influencing the acquisition of rodent carrion by vertebrate scavengers and decomposers. Canadian Journal of Zoology, 82: 502-509.

Eubanks M.D., Lin C. \& Tarone A.M., 2019. The role of ants in vertebrate carrion decomposition. Food Webs, 18: e00109.

Gruner S.V., Slone D.H. \& Capinera J.L., 2007. Forensically important Calliphoridae (Diptera) associated with pig carrion in rural north-central Florida. Journal of Medical Entomology, 44: 509-515.

Hager S.B., Cosentino B.J. \& McKay K.J., 2012. Scavenging affects persistence of avian carcasses resulting from window collisions in an urban landscape. Journal of Field Ornithology, 83: 203-211.

Haxton T., 2000. Road mortality of snapping turtles, Cheyldra serpentina, in central Ontario during their nesting period. Canadian Field Naturalist, 114: 106110.

Inger R., Cox D.T.C., Per E., Norton B.A. \& Gaston K.J., 2016. Ecological role of vertebrate scavengers in urban ecosystems in the UK. Ecology and Evolution, 6: 7015-7023. https://doi.org/10.1002/ece3.2414

Komar D. \& Beattie O., 1998. Identifying bird scavenging in fleshed and dry remains. Canadian Society of Forensic Science Journal, 31: 177-188. https://doi. org/10.1080/00085030.1998.1075117

Kreitlow K., 2010. Insect succession in a natural environment. In: Byrd J.H. \& Castner J. L., Forensic Entomology: The Utility of Arthropods in legal investigations. CRC Press, Boca Raton, Florida, 251270.
Kulshrestha P. \& Satpathy D.K., 2001. Use of beetles in forensic entomology. Forensic Science International, 120: $15-17$.

Melis C., Teurlings I., Linnell J.D.C., Andersen R. \& Bordoni A., 2004. Influence of deer carcass on Coleopteran diversity in a Scandinavian boreal forest: a preliminary study. European Journal of Wildlife Research, 50: 146-149. https://doi.org/10.1007/s10344004-0051-2

Michaud J. \& Moreau G., 2017. Facilitation may not be an adequate mechanism of community succession on carrion. Oecologia, 183: 1143-1153. https://doi.org/ 10.1007/s00442-017-3818-3

O’Brien R.C., Forbes S.L., Meyer J. \& Dadour I.R., 2007. A preliminary investigation into the scavenging activity on pig carcasses in Western Australia. Forensic Science, Medicine and Pathology, 3: 194199.

Perez A.E., Haskell N.H. \& Wells J.D., 2016. Commonly used intercarcass distances appear to be sufficient to ensure independent of carrion insect succession pattern. Annals of the Entomological Society of America, 109: 72-80.

Pokines J. \& Pollock C., 2018. The small scavenger guild of Massachusetts. Forensic Anthropology, 1: 52-67. https://doi.org/10.5744/fa.2018.0005

Pomezanski D. \& Bennett L., 2018. Developing recommendations for monitoring wildlife underpass usage using trail cameras. Environmental Monitoring and Assessment, 190: 413. https://doi.org/10.1007/ s10661-018-6794-0

Rochefort S., Giroux M., Savage J. \& Wheeler T.A., 2015. Key to the forensically important Piophilidae (Diptera) in the Nearctic region. Canadian Journal of Arthropod Identification, 27: 1- 37. https://doi.org/ 10.3752/cjai.2015.27

Row J.R., Blouin-Demers G. \& Weatherhead P.J., 2007. Demographic effects of road mortality in Black ratsnake (Elaphe obsoleta). Biological Conservation, 137: 117-124. https://doi.org/10.1016/j.biocon.2007. 01.020

Schlichting P.E., Love C.N., Webster S.C. \& BeasleyJ. C., 2019. Efficiency and composition of vertebrate scavengers at the land-water interface in the Chernobyl Exclusion Zone. Food Webs, 18: e00107. https://doi.org/10.1016/j.fooweb.2018.e00107

Schwartz A.L.W., Williams H.F., Chadwick E., Thomas, R.J. \& Perkins S.E., 2018. Roadkill scavenging behavior in an urban environment. Journal of Urban Ecology, 4: 1-7.

Shannon G., Lewis J.S. \& Gerber B.D., 2014. Recommended survey designs for occupancy modeling using motion-activated cameras: insights from empirical wildlife data. PeerJ, 2:e532. https://doi.org/10. 7717/peerj.532 
Schoenly K.G., Haskel N.H., Mills D.K., Bieme-Ndi C., Larsen K. \& Lee Y., 2006. Recreating death's acre in the school yard. Using pig carcasses as model corpses to teach concepts of forensic entomology and ecological succession. American Biology Teacher, 68: 402-410.https://doi.org/10.1662/0002-7685(2006)68 [402:RDAITS]2.0.CO;2

Smith K. \& Wall R., 1997. The use of carrion as breeding sites by the blowfly Lucilia sericata and other Calliphoridae. Medical and Veterinary Entomology, 11: 38- 44.

Smith L.L. \& Dodd C.K., 2003. Wildlife mortality on U.S. highway 441 across Paynes praire, Alachua county, Florida. Florida Scientist, 66: 128-140.
VanLaerhoven S.L. \& Anderson G.S., 1999. Insect succession on buried carrion in two biogeoclimatic zones of British Columbia. Journal of Forensic Science, 44: 32-43.

Watson E.J. \& Carlton C.E., 2005a. Succession of forensically significant carrion beetle larvae on large carcasses (Coleoptera: Silphidae). Southeastern Naturalist, 4: 335-346. https://doi.org/10.1656/15287092(2005)004[0335:SOFSCB]2.0.CO;2

Watson E.J. \& Carlton C.E., 2005b. Insect succession and decomposition of wildlife carcasses during fall and winter in Louisiana. Journal of Medical Entomology, 42: 193-203. https://doi.org/10.1603/0022-2585 (2005)042[0193:ISADOW]2.0.CO;2 